\title{
A simple semipaced 3-minute chair rise test for routine exercise tolerance testing in COPD
}

This article was published in the following Dove Press journal:

International Journal of COPD

23 September 2014

Number of times this article has been viewed

\author{
Bernard Aguilaniu',2 \\ Hubert Roth ${ }^{3}$ \\ Jesus Gonzalez-Bermejo ${ }^{4}$ \\ Marie Jondot ${ }^{5}$ \\ Jocelyne Maitre ${ }^{5}$ \\ François Denis ${ }^{6}$ \\ Thomas Similowski ${ }^{4,7}$ \\ 'Medicine Faculty, Université Joseph \\ Fourier, Grenoble, France; ${ }^{2}$ McGill \\ University, Montreal, Canada; ${ }^{3}$ Centre \\ de Recherche en Nutrition Humaine \\ Rhône-Alpes, CHU Grenoble, France; \\ ${ }^{4}$ Assistance Publique-Hôpitaux de \\ Paris, Groupe Hospitalier Pitié- \\ Salpêtrière, Respiratory and Intensive \\ Care Medicine, Paris, France; ${ }^{5} \mathrm{Clinique}$ \\ Universitaire de Pneumologie, $\mathrm{CHU}$ \\ Grenoble, France, Grenoble, France; \\ ${ }^{6}$ Boehringer Ingelheim, ${ }^{7}$ Université \\ Paris, Paris, France
}

\section{Video abstract}

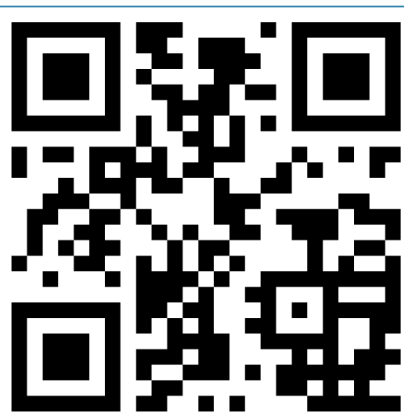

Point your SmartPhone at the code above. If you have a QR code reader the video abstract will appear. Or use: http://dvpr.es/IncxGai

Correspondence: Bernard Aguilaniu Medicine Faculty, Université Joseph Fourier, BP 53, 3804I GRENOBLE CEDEX 9, France

Tel +330680984l 46

Email b.aguilaniu@me.com
Abstract: The functional work capacity of chronic obstructive pulmonary disease (COPD) patients is usually assessed with walk tests such as the 6-minute walk test (6MWT) or the shuttle test. Because these exercise modalities require a controlled environment which limits their use by pulmonologists and severely restricts their use among general practitioners, different modalities of a short ( 1 minute or less) sit-to-stand test were recently proposed. In this study, we evaluated a new modality of a semipaced 3-minute chair rise test (3CRT) in 40 patients with COPD, and compared the reproducibility of physiological responses and symptoms during the 3CRT and their interchangeability with the 6MWT. The results demonstrate that physiological variables, heart rate, pulse oxygen saturation, work done, and symptoms (Borg dyspnea and fatigue scores), during the 3CRT were highly reproducible, and that the physiological responses and symptoms obtained during the $3 \mathrm{CRT}$ and the $6 \mathrm{MWT}$ were interchangeable for most patients. Moreover, these preliminary data suggest that patients able to perform more than 50 rises during 3 minutes had no significant disability. The simplicity and ease of execution of the 3CRT will facilitate the assessment of exercise symptoms and disability in COPD patients during routine consultations with pulmonologists and general practitioners, and will thus contribute to the improved management of COPD patients.

Keywords: exercise test, disability, routine monitoring, chair test

\section{Introduction}

The six-minute walk test (6MWT) is an established procedure to estimate functional exercise capacity in patients with a variety of diseases. For patients suffering from chronic obstructive pulmonary disease (COPD), the 6MWT is commonly applied as the exercise component of the BODE prognostic index. ${ }^{1}$ It retains satisfactory prognostic value and has recently been recommended to general practitioners to assess the functional status of COPD patients. ${ }^{2}$ In COPD patients, a reduced 6MWT distance is associated with increased mortality, ${ }^{3,4}$ a higher risk of exacerbations, ${ }^{5}$ and reduced levels of activities of daily living. ${ }^{6,7}$ In clinical practice, the 6MWT is an important method used to objectively evaluate improvement of symptomatic (dyspnea or fatigue) and physiological responses such as distance walking, pulse oxygen saturation $\left(\mathrm{SpO}_{2}\right)$, and heart rate (HR) after a therapeutic intervention.

Despite the use of standardized procedures, however, a recent multicenter study identified high variability in the $6 \mathrm{MWT}$ performance among the centers. ${ }^{4}$ Moreover, many factors unrelated to the patient's physical performance can influence the test outcome, including the mood, attitude, and motivation of both patient and technician. Moreover, the 6MWT is difficult to implement as a routine clinical activity, where it is often difficult to maintain the quality criteria of the test. 
For these reasons, sit-to-stand tests (STST) are used by clinicians to evaluate a variety of medical conditions. ${ }^{8-10}$ The brevity of the test and its ability to measure physiological outcomes are of particular interest. ${ }^{11}$ Several variants of the STST exist, but in general, patients are instructed to rise and sit as many times as possible within a short period (10 to 60 seconds). Overall, the simplicity and low cost of the STST provide advantages over other potential field substitutes such as the grocery shelving task or the paced step test, which require standardized environments. ${ }^{12,13}$ Usually, these STST showed significant correlations with established tests for exercise capacity such as the distance walked during 6 minutes $(r=0.75)^{14}$ or lower limb muscular strength $(r=0.38),{ }^{15}$ suggesting a link between simple exercise tests and clinical outcomes. For example, Puhan et a ${ }^{16}$ recently confirmed in a prospective cohort of 409 COPD patients that patients with a maximal performance of $11.8 \pm 6.3$ rises during 1 minute had a higher 2-year risk of mortality (but not of exacerbations) than those with $19.5 \pm 8.7$ rises. These authors concluded that availability of such a simple test may close an important gap in the evaluation of the prognosis of COPD patients across different settings. However, readers must realize that patients who were not able to perform more than 12 rises during 1 minute had a very limited maximal mechanical and metabolic power, estimated near 40 watts or $10 \mathrm{~mL} \mathrm{O} \cdot \mathrm{min}^{-1} \cdot \mathrm{kg}^{-1}$ (for $75 \mathrm{~kg}$ ), respectively, which is a clinically evident condition to suspect a high risk of mortality. Therefore, in addition to short STST, it would be extremely valuable to have an alternative walking test that could realistically be performed during a standard consultation and that would provide physiological and symptomatic responses comparable to those observed during the $6 \mathrm{MWT}^{16}$ (or shuttle test). In addition to the predictive clinical outcomes, such a test would facilitate identification of COPD-related physical disability and thus improve routine clinical management of the disease.

We hypothesized that a 3-minute chair rise test (3CRT) elicits symptomatic and physiological responses similar to those observed with walking tests, notably the 6MWT. To test this hypothesis and the feasibility of this kind of exercise, we performed three modalities of a 3CRT in a convenient and limited sample of 40 patients with stable COPD. The three modalities differed only in the number of chair rises imposed during the first minute $(12,15$, or 20 [3CRT-12, 3CRT-15, and 3CRT-20, respectively]), and the tests were repeated 10 days later to ensure reproducibility. The choice to fix a rhythm over the first minute is only based on our observation that this modality can reduce the variability due to patient comportment at the time of the start of an exercise test. We also compared the patients' physiological and symptomatic responses during the $3 \mathrm{CRT}$ and $6 \mathrm{MWT}$ performed on the same day. This initial report strives to provide physiological rational and experimental evidence to find the best compromise between simplicity and robustness for a repeatable functional evaluation exercise with potential clinical and physiological consistency.

\section{Materials and methods Patients}

The study was approved by the ethical committee of the University Hospital Grenoble. Patients received detailed information about the study and gave written consent to participate. Table 1 shows the anthropometric measurements and functional status (for at least 8 weeks) of the 40 stable COPD patients recruited during a current consultation. Only patients with a functional limitation of the lower limbs were excluded from the study. These patients were mainly classified as Global Initiative for Chronic Obstructive Lung Disease (GOLD) II and III, and three patients were GOLD IV and I. Therefore, we pooled the results of GOLD I + II and GOLD III + IV. ${ }^{17}$

\section{Study design}

Patients made two visits $\left(\mathrm{V}_{1}\right.$ and $\left.\mathrm{V}_{2}\right)$ separated by 2 to 10 days. At each visit, patients were examined to assess clinical and functional respiratory stability and then asked to perform the 6MWT, 3CRT-12, 3CRT-15, and 3CRT-20 in succession.

The order of the tests was not randomized, but each exercise test was separated by at least 20 minutes, even if $\mathrm{HR}$ and $\mathrm{SpO}_{2}$ had returned to baseline values before the end of the interval.

At $\mathrm{V}_{1}$, patients completed three self-reported instruments to assess 1) dyspnea according to the modified Medical Research Council dyspnea scale for the calculation of BODE index,,$^{18}$ 2) health impairment status using the St George's Respiratory Questionnaire, ${ }^{19}$ and 3) disability due to dyspnea with the DIsability RElated to Copd Tool (DIRECT). ${ }^{20}$ The latter questionnaire, which assesses the deficiency due to dyspnea in COPD patients, was recently validated in comparison with other references (Saint George's Respiratory Questionnaire activity and the London Handicap Scale) with a high Cronbach's alpha coefficient (0.95).

\section{Resting pulmonary function and 6MWT}

Resting pulmonary function and the 6MWT were performed at $\mathrm{V}_{1}$ and $\mathrm{V}_{2}$. The 6MWT was performed, according to American Thoracic Society statement, ${ }^{21}$ twice during $V_{1}$ to 
Table I Anthropometric, clinical, and functional characteristics of the COPD patients

\begin{tabular}{|c|c|c|c|c|}
\hline & $\begin{array}{l}\text { All } \\
(\mathrm{N}=40)\end{array}$ & $\begin{array}{l}\text { GOLD I-II } \\
(n=3,17)\end{array}$ & $\begin{array}{l}\text { GOLD III-IV } \\
(n=17,3)\end{array}$ & $P$-value \\
\hline Age, year & $65.0 \pm 10.2$ & $66.0 \pm 11.2$ & $64.0 \pm 9.4$ & 0.55 \\
\hline Body mass, kg & $71.4 \pm 13.6$ & $75.2 \pm 14.7$ & $67.6 \pm 11.7$ & 0.08 \\
\hline Height, cm & $166.4 \pm 7.6$ & $167.0 \pm 7.5$ & $165.8 \pm 7.8$ & 0.62 \\
\hline $\mathrm{BMI}, \mathrm{kg} \cdot \mathrm{m}^{-2}$ & $25.8 \pm 4.7$ & $27.0 \pm 5.2$ & $24.5 \pm 3.5$ & 0.09 \\
\hline $\begin{array}{l}\text { Ex-smoking, } \\
\text { pack } \cdot y^{-1}\end{array}$ & $41.6 \pm 20.3$ & $45 \pm 24.3$ & $38.1 \pm 15.3$ & 0.28 \\
\hline $\mathrm{FEV}_{1}, \mathrm{~L}$ & $1.42 \pm 0.47$ & I. $.77 \pm 0.37$ & $1.06 \pm 0.22 *$ & $<0.000$ I \\
\hline $\begin{array}{l}\mathrm{FEV}_{1}, \\
\% \text { predicted }\end{array}$ & $53.7 \pm 16.4$ & $67.0 \pm 11.0$ & $40.4 \pm 7.4^{*}$ & $<0.000$ I \\
\hline FVC, L & $2.76 \pm 0.64$ & $3.05 \pm 0.66$ & $2.48 \pm 0.48^{*}$ & 0.003 \\
\hline $\begin{array}{l}\text { FVC, } \\
\% \text { predicted }\end{array}$ & $82.9 \pm 17.7$ & $91.6 \pm 19.3$ & $74.1 \pm 10.5^{*}$ & 0.001 \\
\hline $\mathrm{FEV}_{\mathrm{I}} / \mathrm{FVC}, \%$ & $50.8 \pm 9.8$ & $58.3 \pm 5.9$ & $43.3 \pm 6.6^{*}$ & $<0.000$ I \\
\hline $\begin{array}{l}\mathrm{FEV} / \mathrm{FVC}, \\
\% \text { predicted }\end{array}$ & $67.3 \pm 13.4$ & $77.3 \pm 8.5$ & $57.2 \pm 9.2^{*}$ & $<0.000$ I \\
\hline $\begin{array}{l}\text { TLC, } \\
\% \text { predicted }\end{array}$ & $125.3 \pm 21.7$ & $115.3 \pm 16.9$ & $135.3 \pm 21.6 *$ & 0.002 \\
\hline $\begin{array}{l}\mathrm{RV}, \\
\% \text { predicted }\end{array}$ & $180.9 \pm 47.6$ & $150 \pm 23.2$ & $211.9 \pm 45.8^{*}$ & $<0.0001$ \\
\hline $\begin{array}{l}\text { RV/TLC, } \\
\% \text { predicted }\end{array}$ & $138.6 \pm 20$ & $125.3 \pm 12.3$ & $151.8 \pm 17.4^{*}$ & $<0.0001$ \\
\hline $\begin{array}{l}\text { FRC, } \\
\% \text { predicted }\end{array}$ & $|63.9 \pm 4|$ & $140.32 \pm 27.4$ & $187.4 \pm 39.2^{*}$ & 0.0001 \\
\hline $\begin{array}{l}\mathrm{DLCO}, \\
\mathrm{mL} \mathrm{CO} \cdot \mathrm{min}^{-1} \text {. } \\
\mathrm{mmHg}{ }^{-1}\end{array}$ & $|2.1 \pm 4|$. & $14.1 \pm 3.8$ & $10.2 \pm 3.4^{*}$ & 0.001 \\
\hline $\begin{array}{l}\text { DLCO, \% } \\
\text { predicted }\end{array}$ & $50.7 \pm 16.7$ & $58.7 \pm 15.0$ & $42.8 \pm 14.6^{*}$ & 0.002 \\
\hline $\mathrm{PaO}_{2}, \mathrm{mmHg}$ & $71.3 \pm 6.5$ & $71.7 \pm 7.3$ & $70.9 \pm 5.8$ & 0.70 \\
\hline $\mathrm{PaCO}_{2}, \mathrm{mmHg}$ & $37.4 \pm 3.3$ & $36.7 \pm 2.9$ & $38.0 \pm 3.7$ & 0.21 \\
\hline 6MWT, m & $442.2 \pm 73.5$ & $475.8 \pm 75.8$ & $4 \mid 8.1 \pm 78.8^{*}$ & 0.024 \\
\hline BODE & $2.37 \pm 1.61$ & $1.12 \pm 1$ & $3.56 \pm 1.10 *$ & $<0.000$ I \\
\hline DIRECT & $12.0 \pm 5.9$ & $9.2 \pm 5.4$ & $15.1 \pm 5^{*}$ & 0.001 \\
\hline MRC & $1.5 \pm 0.9$ & $1.12 \pm 0.9$ & $1.89 \pm 0.8^{*}$ & 0.008 \\
\hline SGRQ Total & $42.0 \pm 16.2$ & $35.6 \pm 16.2$ & $49.1 \pm 13.2^{*}$ & 0.016 \\
\hline $\begin{array}{l}\text { Physical } \\
\text { activity }\end{array}$ & $58.7 \pm 18.6$ & $5 \mathrm{I} \pm 20.0$ & $67.4 \pm 12.5^{*}$ & 0.006 \\
\hline Symptom & $44.9 \pm 21.6$ & $38.1 \pm 19.6$ & $52.1 \pm 21.9$ & 0.054 \\
\hline Impairment & $31.7 \pm 15.0$ & $26.1 \pm 14.4$ & $37.6 \pm 13.7^{*}$ & 0.02 \\
\hline
\end{tabular}

Notes: *Represents significant difference between GOLD I-II and GOLD III-IV groups. Presented as mean \pm standard deviation.

Abbreviations: 6MWT, 6-minute walk test; BMI, body mass index; DIRECT, DIsability RElated to Copd Tool; DLCO, diffusing capacity for carbon monoxide; $\mathrm{FEV}_{\text {}}$, forced expiratory volume in I second; FRC, forced residual capacity; FVC, forced vital capacity; GOLD, Global Initiative for Chronic Obstructive Lung Disease; MRC, Medical Research Council; $\mathrm{PaO}_{2}$, partial pressure of oxygen; $\mathrm{PaCO}_{2}$; partial pressure of carbon dioxide; RV, residual volume; SGRQ, St George's Respiratory Questionnaire; TLC, total lung capacity; $y$, year.

assess immediate repeatability, and the best result was used for comparisons and as a reference for subsequent analysis.

\section{Description of the 3CRT}

While the patient was sitting at rest on a standard chair (floor to seat height $48 \mathrm{~cm}$ ), the instructions for the conduct of the exercise and for the comprehensive use of the Borg scale ${ }^{22}$ (dyspnea and fatigue) were explained as follows:

The exercise is to stand and sit during 3 minutes. Throughout the test you must keep your hands on your hips. I'll give you the rhythm during the first minute by a simple verbal order: "sit", "stand" (or by doing the sit-to-stand with you). During the last 2 minutes you will try to rise and sit as many times as possible. I will tell you the remaining time verbally: "only another minute and 30 seconds", "only another minute", "only another 30 seconds". At any time, you can slow down or speed up. If the exercise is too difficult, you can also stop and start again. You can also decide to permanently stop the test before the end of 3 minutes if you feel too tired or breathless.

At the end of the exercise, physiological data $\left(\mathrm{SpO}_{2}, \mathrm{HR}\right)$ and symptoms (dyspnea and leg fatigue with the Borg scale) were recorded.

\section{Statistical analysis}

Distribution symmetries were assessed graphically using box plots, and normality was verified using the Shapiro-Wilk test, as necessary. Quantitative data are presented as means and standard deviations. The characteristics of the patients in the two groups (GOLD I-II and GOLD III-IV) were compared with the nonpaired Student's $t$-test for normal variables and with the Mann-Whitney test for other variables. After completion of the 3CRT, patients were divided into four groups according to the quartiles (quartiles are values and not ranges) of the frequency distribution of the total number of rises, and analysis of variance was used to compare the respiratory parameters among the four groups.

To assess repeatability, we modeled the observations by a two-way mixed-effect analysis of variance (ANOVA) model where a measurement on a subject at time $j\left(\mathrm{~V}_{1}\right.$ or $\left.\mathrm{V}_{2}\right)$ is regarded as the sum of a random subject effect, a fixed time effect, a random subject-time interaction effect, and a random error. When the above ANOVA model proved to be adequate, repeatability was evaluated via the intraclass correlation coefficient. We have also assessed repeatability between the measurements at the two times by looking for systematic differences or biases between the two via the method of differences proposed by Bland and Altman. ${ }^{23}$

In studies comparing two methods, generally, the main objective is to quantify the extent of agreement between the methods and determine if they agree sufficiently well to justify their interchangeable use. Among the several statistical approaches for evaluating agreement and interchangeability 
between two methods of measurements, those based on linear least squares regression are very popular. ${ }^{24,25}$ Hence, to determine if maximal physiological responses $\left(\mathrm{SpO}_{2}\right.$, HR) were interchangeable between the 6MWT and 3CRT, we evaluated the agreement between these responses using a Bland-Altman plot. ${ }^{23}$ To strengthen the conclusion of the similarities between physiological variables measured at the end of the two exercises, we applied two others regressions: the Deming and the Passing-Bablok regressions. ${ }^{26,27}$

Wilcoxon tests were used to determine whether maximal Borg rating symptoms (range 0-10) were different at the end of the 6MWT and 3CRT. Finally, baseline parameters were tested as predictive factors of the 3CRT-12 and 3CRT20 results with a multivariate linear regression model using stepwise backward elimination to select the significant parameters. All statistical tests were done with Stata 12 (StataCorp LP, College Station, TX, USA), except for the comparison of methods, which was performed with the R package MethComp (Bland-Altman, Deming, and PBreg). ${ }^{28}$

\section{Results}

All patients were able to perform all of the exercise tests (3CRT and 6MWT). Anthropometric, clinical, and functional characteristics of the COPD patients are shown in Table 1.

\section{Feasibility and repeatability of performance in the 3CRT}

ANOVA mixed-effect modeling seemed adequate and showed that for the 3CRT $(12,15,20)$ and the 6MWT, the visit factor had no effect (no significant differences between the readings of any subject across visits) and reflected only the variability between subjects (rows 4 to 6 of Table 2). This was also confirmed by the nonsignificant bias in the difference between the readings at the two visits (row 3 of Table 2).

The repeatability of the total number of rises was very high, with an intraclass correlation (ICC) $>0.80$ for all modalities (Table 3 ). Three patients (all GOLD IV) were unable to follow the imposed 20-rise rhythm (two due to breathlessness and one for knee pain), and they stopped before the end of the third minute. In contrast, for the 3CRT-12 and 3CRT-15 modalities, all patients were able to follow the rhythm of rises during the first minute and to complete the test (Figure 1; Table S1).

\section{Repeatability and interchangeability of maximal physiological and symptomatic responses in the 3CRT and 6MWT}

Table 4 shows that for this population, the maximal physiological responses $\left(\mathrm{SpO}_{2}, \mathrm{HR}\right)$ were similar at the end of the 6MWT and the three 3CRT modalities. The repeatability of $\mathrm{SpO}_{2}$ and $\mathrm{HR}$ was good for all four tests ( $\mathrm{ICC}>0.80$ ). The repeatability of the symptomatic responses was better for the 3CRT $(12,15,20)$ modalities than the 6MWT, but the ICC values were less than 0.80 (Table 3 ). The interchangeability of the maximal values for $\mathrm{SpO}_{2}$ and $\mathrm{HR}$ was confirmed by each statistical test described in the methods (an example of these regression analyses is shown for maximal $\mathrm{SpO}_{2}$ at the end of the 3CRT-20 in Figure S1). Table 5 shows that for the majority of patients, the intensity of dyspnea was higher after the 3CRT than after the 6MWT. Notably, $56 \%$ of patients had higher Borg dyspnea scores, and 64\% had higher fatigue scores at the end of the 3CRT-20 than after the 6MWT.

\section{Outcomes of the 3CRT classified by performance quartiles (total number of rises)}

Table 6 reports the main clinical and functional characteristics of patients classified in quartiles (least [Q1] to most severely [Q4] impaired) of the maximal performance in the 3CRT-20 (number of rises in 3 minutes). Only the functional parameters, including the 6MWT, BODE index, and DIRECT score, were significantly different between each quartile. Figure 1 and Table S1 show the spontaneous number of rises at the end of each minute of each modality. The most severely impaired

Table 2 Repeatability of the 6MWT and each modality of the 3CRT

\begin{tabular}{lllll}
\hline & 3CRT-I 2 & 3CRT-I 5 & 3CRT-20 & 6MWT (m) \\
\hline Performance at $\mathrm{V}_{1}$ & $48.8 \pm 10$ & $49.5 \pm 10.2$ & $55.3 \pm I 1.1$ & $447 \pm 77$ \\
Bias $\left(\mathrm{V}_{1}\right.$ versus $\left.\mathrm{V}_{2}\right)$ & $1.65(-0.24 ; 3.54)$ & $-0.64(-2.17 ; 0.89)$ & $-0.37(-2.04 ; 1.30)$ & $-4.73(-13.44 ; 3.99)$ \\
Adjusted R-squared & 0.83 & 0.94 & 0.92 & 0.90 \\
$F$ & 10.32 & 30.8 & 22 & 19.07 \\
Probability $>F$ & 0.000 & 0.000 & 0.000 & 0.000 \\
\hline
\end{tabular}

Notes: Repeatability of the maximal number of rises between $V_{1}$ and $V_{2}$ in the three $3 C R T$ modalities defined by the imposed frequency of rises during the first minute $(12$, 15 , or 20); the repeatability of the 6MWT is shown for comparison (performance measured in meters covered); the bias is given by Bland and Altman tests; ${ }^{23}$ the adjusted $R$-squared and the significant $F$-test validate the use of mixed-effect analysis of variance (ANOVA) to calculate the intraclass correlation coefficient. Presented as mean \pm standard deviation. Abbreviations: $3 C R T$, 3-minute chair rise test; 6MWT, 6-minute walk test; $\mathrm{V}_{1}$, first visit; $\mathrm{V}_{2}$, second visit. 
Table 3 Repeatability of $\mathrm{SpO}_{2}$, HR, dyspnea, fatigue, and number of rises

\begin{tabular}{llllll}
\hline & $\mathrm{SPO}_{2}$ & HR & Dyspnea & Fatigue & $\begin{array}{l}\text { Distance/ } \\
\text { number of rises }\end{array}$ \\
\hline 6MWT & $0.93(0.82-0.97)$ & $0.86(0.76-0.92)$ & $0.54(0.25-0.81)$ & $0.77(0.61-0.87)$ & $0.96(0.90-0.99)$ \\
3 CRT-12 & $0.83(0.7 \mathrm{I}-0.91)$ & $0.81(0.64-0.91)$ & $0.57(0.35-0.76)$ & $0.66(0.44-0.83)$ & $0.82(0.61-0.93)$ \\
3 CRT-15 & $0.94(0.89-0.97)$ & $0.79(0.62-0.90)$ & $0.62(0.41-0.79)$ & $0.66(0.41-0.84)$ & $0.90(0.82-0.94)$ \\
3 CRT-20 & $0.92(0.85-0.95)$ & $0.81(0.64-0.91)$ & $0.73(0.55-0.85)$ & $0.68(0.43-0.86)$ & $0.90(0.82-0.95)$ \\
\hline
\end{tabular}

Note: Intraclass correlation coefficient [95\% confidence interval] given by a mixed-effect model.

Abbreviations: 3CRT-I2, 3-minute chair rise test - 12 rises; 3CRT-15, 3-minute chair rise test - 15 rises; 3CRT-20, 3-minute chair rise test - 20 rises; HR, heart rate; $6 \mathrm{MWT}$, 6-minute walk test; $\mathrm{SpO}_{2}$, pulse oxygen saturation.

patients (Q4) were able to sustain the 12-rise rhythm over the second and third minutes but showed a dramatically reduced spontaneous rhythm (below 12) in the final 2 minutes of the 3CRT-20. As a consequence of the spontaneous rhythm adjustments, the total number of chair rises for the Q4 patients was similar in the three modalities. Conversely, Q1 patients immediately increased their spontaneous rhythm during the 3CRT-12 and 3CRT-15 to approximately the same rhythm observed during the 3CRT-20, resulting in a significantly better total performance in the 3CRT-20 than in the 3CRT-12. This trend was also observed for the Q2 patients during the 3CRT-20. The maximal number of rises in the 3CRT was predicted by a multivariate linear regression model including age, body mass index, transfer factor for carbon monoxide (\%), and DIRECT score $\left(r^{2}=0.50\right.$ and 0.56 for 3CRT- 12 and 3CRT-20, respectively) (Table S2).

\section{Discussion}

This exploratory study demonstrated that 1) the 3CRT, an adapted STST, elicited reproducible sensory and physiological responses in a convenient sample of patients with

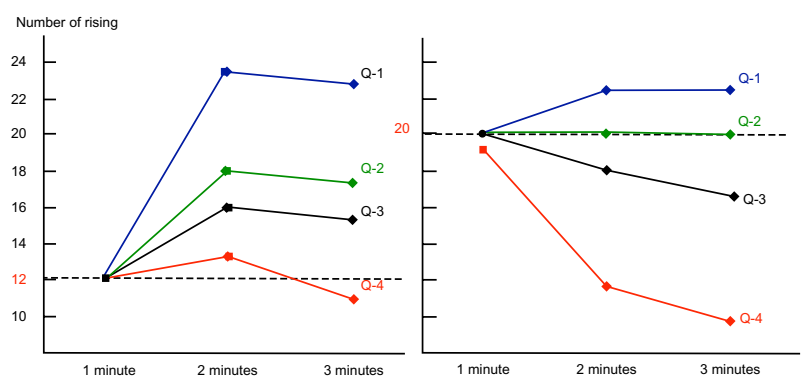

Figure I Number of rises per minute in patients grouped by quartiles (Q) for the 3CRT- 12 and 3CRT-20.

Notes: Patient groups were defined by the overall performance (total number of rises in 3 minutes), with QI to Q4 representing the least to the most severely impaired; the left and right panels show the results when the rhythm imposed during the first minute was 12 and 20 rises, respectively; the graphs show that the more severely impaired patients (Q4) cannot sustain the rate of 20 rises per minute imposed during the first minute; conversely, the least impaired patients (QI) set a spontaneous rhythm of $\sim 22$ rises per minute, whether the rhythm during the first minute was imposed at 12 or 20.

Abbreviations: 3CRT-I2, 3-minute chair rise test - 12 rises; 3CRT-20, 3-minute chair rise test -20 rises.
COPD, and 2) physiological responses measured at the end of the 3CRT were similar to and interchangeable with those obtained at the end of the 6MWT, whereas Borg dyspnea and fatigue scores were generally higher after the 3CRT. Thus, the 3CRT has the potential to be at least as successful as the 6MWT for evaluating exercise symptoms and detecting a significant loss of work capacity, the two being major components of disability in an individual COPD patient.

\section{Detecting disability in COPD}

The International Classification of Functioning, Disability and Health promoted by the World Health Organization noted that reduced functional capacity is a pivotal determinant of disability and can contribute to activity restriction and reduced participation during chronic disease. ${ }^{29}$ In COPD patients in particular, such restrictions are relatively independent of the decline in respiratory function ${ }^{30}$ and are the strongest predictor of all-cause mortality. ${ }^{31}$ Two of the major treatment goals for COPD patients are to improve their functional status and their participation and performance in physical activities, which are both independent predictors of exacerbations, hospital admissions, quality of life, and mortality. ${ }^{31,32}$ It is therefore essential that the general practitioner or lung specialist is able to easily detect disability and evaluate its magnitude and determinants. Activity and participation restrictions are generally explored by questionnaires and activity monitors for research purposes.$^{33}$ To complement

Table 4 End exercise values for $\mathrm{SpO}_{2}$ and $\mathrm{HR}$ during the 6MWT and each 3CRT modality performed at $\mathrm{V}_{2}$

\begin{tabular}{lll}
\hline & $\mathrm{SpO}_{2}(\%)$ & HR (bpm) \\
\hline 6MWT & $89.9 \pm 4.4$ & $\mathrm{III} \pm 16$ \\
3CRT-12 & $90.6 \pm 4.4$ & $\mathrm{III} \pm 15$ \\
3 CRT-15 & $90.4 \pm 4.4$ & $\mathrm{II} 2 \pm 13$ \\
3 CRT-20 & $90.2 \pm 4.8$ & $\mathrm{II} 4 \pm 13^{*}$ \\
\hline
\end{tabular}

Notes: Significant difference in HR between the 6MWT and 3CRT-20 groups; $* P<0.02$ (Student's $t$-test). Presented as mean \pm standard deviation.

Abbreviations: 3CRT-12, 3-minute chair rise test -12 rises; 3CRT-15, 3-minute chair rise test -15 rises; 3CRT-20, 3-minute chair rise test -20 rises; HR, heart rate; $6 \mathrm{MWT}$, 6-minute walk test; $\mathrm{SpO}_{2}$, pulse oxygen saturation; $\mathrm{V}_{2}$, second visit. 
Table 5 Borg dyspnea and fatigue scores ${ }^{22}$ at the end of the 6MWT and each 3CRT modality

\begin{tabular}{lll}
\hline & $\begin{array}{l}\text { Dyspnea median } \\
\left(\mathbf{Q}, \mathbf{Q}_{3}\right)\end{array}$ & $\begin{array}{l}\text { Fatigue median } \\
(\mathbf{Q} \text { I, Q3) }\end{array}$ \\
\hline 6MWT & $3(2,4.5)$ & $3(2,4)$ \\
3 CRT-I2 & $3(3,4)$ & $3(3,5)$ \\
3 CRT-I5 & $3(3,5)^{*}$ & $4(3,5)^{* *}$ \\
3 CRT-20 & $4(3,5.5)^{* *}$ & $4(3,6)^{* * *}$ \\
\hline
\end{tabular}

Notes: Numbers are the medians and values for the QI and Q3 quartiles of the distribution; the data indicate that a large proportion of patients felt more intense symptoms of dyspnea and fatigue following the 3CRT-20 than the 6MWT; significant differences between the 6MWT and the three modalities of $3 C R T: * P<0.05$; $* * P<0.02$; *** $P<0.001$ (Wilcoxon test).

Abbreviations: 3CRT-12, 3-minute chair rise test - 12 rises; 3CRT-15, 3-minute chair rise test - 15 rises; 3CRT-20, 3-minute chair rise test -20 rises; $6 \mathrm{MWT}$, 6-minute walk test.

these, the patient's work capacity is assessed with different maximal exercise tests (cycling or walking oxygen consumption $\left[\mathrm{VO}_{2}\right]$ ) or with simpler and less expensive field exercise tests in standardized environments. Many field exercise tests have been developed to estimate maximal or submaximal

Table 6 Main clinical and functional characteristics for each quartile of the overall performance in the 3CRT-20

\begin{tabular}{|c|c|c|c|c|}
\hline 3CRT quartiles (Q) & QI & Q2 & Q3 & Q4 \\
\hline \multirow[t]{2}{*}{ number of rises } & $>54$ & $5 I-54$ & $44-50$ & $<44$ \\
\hline & $n=10$ & $n=10$ & $n=9$ & $n=10$ \\
\hline Age & $63 \pm 8.4$ & $61.7 \pm 11$ & $64.7 \pm 9$ & $71.7 \pm 10.6$ \\
\hline Weight & $73.4 \pm 14.9$ & $69.4 \pm 17$ & $67.9 \pm 11.6$ & $74.8 \pm 9.7$ \\
\hline BMI & $27.1 \pm 4.6$ & $25.8 \pm 6$ & $24.3 \pm 3.7$ & $25.5 \pm 3.4$ \\
\hline GOLD I-II (\%) & $70(n=7)$ & $60(n=6)$ & $56(n=5)$ & $20(n=2)$ \\
\hline GOLD III-IV (\%) & $30(n=3)$ & $40(n=4)$ & $44(n=4)$ & $80(n=8)$ \\
\hline 6MWT (m) & $476 \pm 65^{d}$ & $499 \pm 60^{d}$ & $449 \pm 58$ & $386 \pm 65^{a, b}$ \\
\hline \multicolumn{5}{|l|}{ Borg dyspnea } \\
\hline 3CRT & $3.6 \pm I .7^{c, d}$ & $3.65 \pm 0.7^{c, d}$ & $5.2 \pm 2.4^{\mathrm{a}, \mathrm{b}}$ & $5.8 \pm 1.9^{\mathrm{a}, \mathrm{b}}$ \\
\hline 6MWT & $2.9 \pm 1.7^{d}$ & $3.15 \pm 1.4^{\mathrm{d}}$ & $3.5 \pm 1.2$ & $4.1 \pm 2 . I^{a, b}$ \\
\hline \multicolumn{5}{|l|}{ Borg fatigue } \\
\hline $3 C R T$ & $3.9 \pm 2.2^{\mathrm{d}}$ & $3.9 \pm 1.7^{\mathrm{d}}$ & $4.9 \pm 1,5^{\mathrm{a}, \mathrm{b}}$ & $5.4 \pm 2.7^{\mathrm{a}, \mathrm{b}}$ \\
\hline 6MWT & $2 \pm 1.2^{\mathrm{d}}$ & $3.4 \pm 2.9$ & $3.4 \pm 2.1$ & $3.9 \pm 3.2^{\mathrm{a}}$ \\
\hline \multicolumn{5}{|l|}{ 3CRT } \\
\hline $\mathrm{SpO}_{2}(\%)$ & $90.4 \pm 4^{\mathrm{c}, \mathrm{d}}$ & $92.4 \pm 2^{\mathrm{c}, \mathrm{d}}$ & $89.6 \pm 3.8^{a, b}$ & $86 \pm 8.5^{\mathrm{a}, \mathrm{b}}$ \\
\hline HR (bpm) & $120 \pm 10.5$ & $121 \pm 13.4$ & $112 \pm 12.3$ & $118 \pm 14$ \\
\hline $\mathrm{FEV}_{1}(\mathrm{~L})$ & $1.43 \pm 0.40$ & $1.57 \pm 0.57$ & $1.56 \pm 0.29$ & $1.12 \pm 0.35$ \\
\hline $\mathrm{FEV}_{\mathrm{I}} / \mathrm{FVC}(\%)$ & $70.9 \pm 14.1$ & $66.1 \pm 13.4$ & $70.4 \pm 12.0$ & $62.4 \pm 14.8$ \\
\hline RV/TLC (\%) & $135.0 \pm 18.4$ & $132.3 \pm 2 \mid .9$ & $|3| .4 \pm 22 . \mid$ & $149.4 \pm 22.0$ \\
\hline TLCO (\%) & $56.5 \pm 14.9$ & $49.6 \pm 12.1$ & $49.1 \pm 20.1$ & $42.9 \pm 16.7$ \\
\hline BODE index' & $1.5 \pm 1.9^{\mathrm{d}}$ & $1.8 \pm 1.0^{\mathrm{d}}$ & $2.1 \pm 1.5$ & $3.9 \pm 1.0^{\mathrm{a}, \mathrm{b}}$ \\
\hline DIRECT $^{20}$ & $9.1 \pm 5.9^{d}$ & $11.4 \pm 6.2$ & $14.4 \pm 5.6$ & $13.6 \pm 5.4^{\mathrm{a}}$ \\
\hline SGRQ total & $38.2 \pm 19.5$ & $40.6 \pm 18.4$ & $44.3 \pm 27.8$ & $47 \pm 10$ \\
\hline
\end{tabular}

Notes: Analysis of variance (ANOVA) shows significant differences between quartiles only for 6MWT $(P<0.002)$, BODE index $(P=0.005)$, and DIRECT score $(P=0.037)$; ${ }^{a, b, c}$ and ${ }^{d}$ indicate significant differences $(P<0.0 \mathrm{I})$ compared with QI, Q2, Q3, and Q4, respectively. Presented as mean \pm standard deviation.

Abbreviations: 3CRT, 3-minute chair rise test; 3CRT-20, 3-minute chair rise test 20 rises; BMI, body mass index; DIRECT, Dlsability RElated to Copd Tool; FEV , forced expiratory volume in I second; FVC, forced vital capacity; GOLD, Global Initiative for Chronic Obstructive Lung Disease; HR, heart rate; 6MWT, 6-minute walk test; SGRQ, St George's Respiratory Questionnaire; $\mathrm{SpO}_{2}$, pulse oxygen saturation; TLC, total lung capacity; TLCO, transfer factor for carbon monoxide; RV, residual volume. work capacity and classify patients according to the mean metabolic power attained. For example, the average power is expressed as the distance traveled during a set time for the 6MWT, and as the time required to perform a specific task for the grocery shelving test. ${ }^{12}$ Regardless of their specific modalities, most field tests are more or less repeatable and correlate logically with the physiological responses. In addition to the physiological and methodological requirements (repeatability, validity, and responsiveness), a field stress test must be easily performed. In this regard, a recent review by Kocks et $\mathrm{al}^{2}$ pointed out that although the 6MWT is the most reliable semi-laboratory tool to assess the global functional capacity of COPD patients, its use is limited by its impracticality. Indeed, the 6MWT requires a corridor without passages that might influence the patient's walking pace. The final performance and reproducibility of the 6MWT depend on the manner in which the investigator conducts the test and the severity of the patient's disease, both of which affect the maximal response. Because these influences are difficult to codify, the 6MWT is moderately repeatable, and the clinically significant threshold varies with the nature and severity of the medical condition. Finally, for a field test to be widely adopted, it must be feasible within the usual environment of the medical consultation, and the patient's physiological and sensory responses must be reproducible.

\section{Repeatability of the physiological and sensory responses of the 3CRT}

To define the most appropriate protocol in terms of feasibility, repeatability, and physiological responses, we developed three 3CRT modalities that varied in the imposed rhythm during the first minute $(12,15$, or 20 rises).

We hypothesized that imposing the frequency of rises during the first minute would reduce the variability associated with different patient behaviors at the start of the test. In addition, the rhythm could be adjusted in the final 2 minutes if the initial rhythm was too high for severely impaired patients. Conversely, for subjects who were less limited by ventilatory constraints and symptoms, the verbal announcement every 30 seconds during the final two minutes encouraged them to increase the rise frequency and allowed them to approach their maximal aerobic power by the end of the 3 minutes. Our results (Figure 1; Table S1) confirm that the less limited patients did indeed make these adjustments. Under these test conditions, we observed a significant repeatability for the number of rises, maximal $\mathrm{SpO}_{2}, \mathrm{HR}$, and dyspnea and muscle fatigue scores. These results suggest that the 3CRT may have better interindividual reproducibility than the 6MWT, and 
this needs to be confirmed in a larger population of COPD patients and in a multicenter study.

\section{Interchangeability of physiological responses and symptoms between the 3CRT and 6MWT}

The significant correlations ( $R=0.54-0.65)$ between the distance covered during the 6MWT and the maximal number of rises during the $3 \mathrm{CRT}(12,15,20)$ demonstrate that the maximal or submaximal power generated by the two tests are more or less correlated, as has been reported in another sitto-stand study. ${ }^{14}$ The physiological responses at the end of the two tests were also highly correlated, and the mean maximal $\mathrm{SpO}_{2}$ and HR were not statistically different, except for HR in 3CRT-20 (Table 4). However, correlations do not signify interchangeability. $R$ measures the linear relationship between the tests, but it cannot detect a bias constant or proportional bias and therefore does not measure the agreement. Furthermore, the $R$-value can be artificially high if the range of data values is wide, as has frequently been observed in previous studies. Other coefficients (intraclass or concordance correlation coefficient) are often used, but these indexes depend on the variability between subjects. Because of these limitations, we tested Deming and Passing-Bablok regressions to examine the interchangeability beyond the statistical power of the regression coefficient. ${ }^{28}$ Indeed, the Deming regression is an orthogonal least squares regression used when measurement errors are present in the two conditions. ${ }^{26}$ Because neither the 6MWT nor 3CRT can be considered as the gold standard for each other, the Deming regression 1) assesses the regression of each measured variable ( $\mathrm{SpO}_{2}$ and $\left.\mathrm{HR}\right)$ on the other and 2) determines if the slope and intercept of the two regression lines are equal to 1 and 0 , respectively. The Deming regression provides an unbiased estimate of the slope. To implement this, the procedure requires the variance ratio of the two methods to be known. In our case, we have used the data from $V_{1}$ to estimate this ratio. The Passing-Bablok regression ${ }^{27}$ is a nonparametric rank regression, where the slope of the regression line is calculated as the median of all possible slopes (Figure S1). It is resistant to outliers but gives an unbiased slope estimate only if the standard deviations for the two methods are of equal size. In this study, all of these complementary approaches converged to predict high interchangeability between physiological responses induced by the 6MWT and 3CRT. If the interchangeability observed during this single center study is confirmed by the results of an ongoing multicenter study, we will conclude that the functional responses induced by these two types of exercise are individually interchangeable. On the other hand, the 3CRT-15 and 3CRT-20 modalities resulted in higher Borg dyspnea and fatigue scores than the 6MWT. These findings may reflect the different types of muscular work required for the 3CRT versus $6 \mathrm{MWT}$ and the subsequent effects on ventilatory responses and the perceived quantity (or quality) of dyspnea and fatigue. These hypotheses must be confirmed by a study with therapeutic interventions or a rehabilitation program.

\section{Physiological characteristics of 3CRT}

An advantage of an STST is it provides the ability to estimate the mechanical and metabolic power performed. The supplied work (joules) is the product of the movement of the mass and the distance. The raised mass is the total body mass less $12 \%$ for the mass of the feet and legs: $M \times 0.88$. For a subject of $175 \mathrm{~cm}$, sitting with horizontal thighs, the sit-to-stand movement from a standard chair represents work of,

$$
\mathrm{M} \times 0.88 \times 0.45 \times 1.3 \mathrm{~kg} \cdot \mathrm{m}
$$

where 1.3 includes 0.3 for the eccentric work of the descent, and 0.45 is the mean length $(\mathrm{m})$ of the thighbone. This estimation is based on measurements of the metabolic efficiency for similar rhythms ( $24 \%$ and $38 \%$ for 12 and 20 rises per minute, respectively) performed in healthy subjects by Asmussen and Bonde-Petersen ${ }^{34}$ and confirmed by our data (not shown). For example, for a rise and descent in 5 seconds (12 rises per minute), the power is,

$$
\mathrm{M} \times 0.88 \times 0.45 \times 1.3 \times 9.81 / 5=\mathrm{M} \times 1.01 \mathrm{~W}=1 \mathrm{~W} \cdot \mathrm{kg}^{-1}
$$

In terms of $\mathrm{VO}_{2}$, each $1 \mathrm{~W} \cdot \mathrm{kg}^{-1}$ increase in metabolic spending represents an additional spending of $12 \mathrm{~mL} \mathrm{O}_{2} \cdot \mathrm{min}^{-1} \cdot \mathrm{kg}^{-1}$ (for a delta efficiency of $24 \%$ ). If the internal work is negligible (in healthy subjects), the total $\mathrm{VO}_{2}$ is estimated to be $\sim 15 \mathrm{~mL} \mathrm{O} \cdot \mathrm{min}^{-1} \cdot \mathrm{kg}^{-1}$ (total $\mathrm{VO}_{2}=$ rest $\mathrm{VO}_{2}\left[3.5 \mathrm{~mL} \mathrm{O}_{2} \cdot \mathrm{kg}^{-1}\right]+$ exercise $\mathrm{VO}_{2}$ ). These estimates remain to be confirmed in an ongoing study conducted in a large population of COPD patients and age-matched healthy subjects.

\section{Limits and weaknesses of the study}

This proof-of-concept study needs to be extended to a larger population of COPD patients to evaluate a potential ceiling effect of the 3CRT. A control group could also help to detect significant exercise intolerance notably in age-paired, mild COPD patients or in smokers suspected to have an 
obstructive pulmonary disease. As for other field tests, it may be interesting to explore if the 3CRT is reflective of activities of daily living. However, a recent study demonstrates that simple tests such as the 6MWT and the STST (and the Zutphen Physical Activity Questionnaire) cannot be used to reliably predict physical activity. ${ }^{35}$

\section{Practical recommendations and further validations}

Because an exercise test gives only partial information on disability, the test should be complemented with specific questionnaires exploring the effects of functional impairment. From the results of this preliminary study, it could be suggested that the patient should first complete a self-administered questionnaire to detect a possible functional impairment (DIRECT) ${ }^{20}$ and then undergo the 3CRT to confirm the questionnaire screening and to estimate the patient's functional capacity. Not only are these two assessments easy to combine, but the multivariate linear analysis indicated that the DIRECT score was one of the main determinants of the final performance of the 3CRT, together with age, body mass index, and transfer factor for carbon monoxide. Using a combination of DIRECT (or other similar questionnaires) and the 3CRT, a significant handicap would be suggested by a DIRECT score greater than 12 and an inability to achieve more than 50 rises during the 3CRT. Moreover, it appears that the 3CRT-20 modality can discriminate between patients who are able to sustain the rhythm imposed during the first minute and those who are not. Thus, these preliminary results suggest that the 3CRT-12 modality should be reserved for patients with more impaired functional status and a DIRECT score of less than 12. However, these assumptions are putative and await further evaluation and validation by a planned study to test the validity and the responsiveness of 3CRT and DIRECT in a standard program of rehabilitation.

\section{Acknowledgments}

We thank Professor Anestis Antoniadis for his valuable statistical advice and Anne M O'Rourke, $\mathrm{PhD}$ for editing the manuscript.

\section{Disclosure}

The authors report no conflicts of interest in this work.

\section{References}

1. Celli BR, Cote CG, Marin JM, et al. The body-mass index, airflow obstruction, dyspnea, and exercise capacity index in chronic obstructive pulmonary disease. N Engl J Med. 2004;350(10):1005-1012.
2. Kocks JW, Asijee GM, Tsiligianni IG, Kerstjens HA, van der Molen T. Functional status measurement in COPD: a review of available methods and their feasibility in primary care. Prim Care Respir J. 2011;20(3): 269-275.

3. Pinto-Plata VM, Cote C, Cabral H, Taylor J, Celli BR. The 6-min walk distance: change over time and value as a predictor of survival in severe COPD. Eur Respir J. 2004;23(1):28-33.

4. Casanova C, Celli BR, Barria P, et al; Six Minute Walk Distance Project (ALAT). The 6-min walk distance in healthy subjects: reference standards from seven countries. Eur Respir J. 2011;37(1): 150-156.

5. Marin JM, Carrizo SJ, Casanova C, et al. Prediction of risk of COPD exacerbations by the BODE index. Respir Med. 2009;103(3): 373-378.

6. Pitta F, Troosters T, Spruit MA, Probst VS, Decramer M, Gosselink R. Characteristics of physical activities in daily life in chronic obstructive pulmonary disease. Am J Respir Crit Care Med. 2005;171(9): 972-977.

7. Chao PW, Ramsdell J, Renvall M, Vora C. Does a history of exercise in COPD patients affect functional status? A study using a lifetime physical activity questionnaire investigates a correlation between exercise and functional status as evidenced by six-minute walk distance. COPD. 2011;8(6):429-436.

8. Bohannon RW. Reference values for the five-repetition sit-to-stand test: a descriptive meta-analysis of data from elders. Percept Mot Skills. 2006;103(1):215-222.

9. Buatois S, Miljkovic D, Manckoundia P, et al. Five times sit to stand test is a predictor of recurrent falls in healthy community-living subjects aged 65 and older. J Am Geriatr Soc. 2008;56(8):1575-1577.

10. Brodin E, Ljungman S, Sunnerhagen KS. Rising from a chair: a simple screening test for physical function in predialysis patients. Scand J Urol Nephrol. 2008;42(3):293-300.

11. Netz Y, Ayalon M, Dunsky A, Alexander N. 'The multiple-sit-tostand' field test for older adults: what does it measure? Gerontology. 2004;50(3):121-126.

12. Hill CJ, Denehy L, Holland AE, McDonald CF. Measurement of functional activity in chronic obstructive pulmonary disease: the grocery shelving task. J Cardiopulm Rehabil Prev. 2008;28(6):402-409.

13. Perrault H, Baril J, Henophy S, Rycroft A, Bourbeau J, Maltais F. Paced-walk and step tests to assess exertional dyspnea in COPD. COPD. 2009;6(5):330-339.

14. Ozalevli S, Ozden A, Itil O, Akkoclu A. Comparison of the Sit-to-Stand Test with 6 min walk test in patients with chronic obstructive pulmonary disease. Respir Med. 2007;101(2):286-293.

15. Jones SE, Kon SS, Canavan JL, et al. The five-repetition sit-to-stand test as a functional outcome measure in COPD. Thorax. 2013;68(11): 1015-1020.

16. Puhan MA, Siebeling L, Zoller M, Muggensturm P, ter Riet G. Simple functional performance tests and mortality in COPD. Eur Respir J. 2013;42(4):956-963.

17. Global initiative for chronic obstructive lung disease. Global strategy for the diagnosis, management and prevention of chronic obstructive lung disease. 2011. http://www.goldcopd.com.

18. Bestall J, Paul E, Garrod R, Garnham R, et al. Usefulness of the Medical Research Council (MRC) dyspnoea scale as a measure of disability in patients with chronic obstructive pulmonary disease. Thorax. 1999;54:581-586.

19. Bouchet C, Guillemin F, Hoang Thi TH, Cornette A, Briancon S. Validation du questionnaire St Georges pour mesurer la qualite de vie chez les insuffisants respiratoires chroniques. Rev Mal Respir. 1996;13:43-46. French.

20. Aguilaniu B, Gonzalez-Bermejo J, Regnault A, et al. Disability related to COPD tool (DIRECT): towards an assessment of COPD-related disability in routine practice. Int J Chron Obstruct Pulmon Dis. 2011;6:387-398.

21. ATS Committee on Proficiency Standards for Clinical Pulmonary Function Laboratories. ATS statement: guidelines for the six-minute walk test. Am J Respir Crit Care Med. 2002;166(1):111-117. 
22. Borg GA. Psychophysical bases of perceived exertion. Med Sci Sports Exerc. 1982;14(5):377-381.

23. Bland JM, Altman DG. Measuring agreement in method comparison studies. Stat Methods Med Res. 1999;8(2):135-160.

24. Johnson R. Assessment of bias with emphasis on method comparison. Clin Biochem Rev. 2008;29(Suppl 1):S37-S42.

25. Lin L, Hedayat AS, Sinha B, Yang M. Statistical methods in assessing agreement: models, issues, and tools. J Am Stat Assoc. 2002;97: $257-270$

26. Linnet K. Evaluation of regression procedures for methods comparison studies. Clin Chem. 1993;39(3):424-432.

27. Passing H, Bablok. A new biometrical procedure for testing the equality of measurements from two different analytical methods. Application of linear regression procedures for method comparison studies in clinical chemistry, Part I. J Clin Chem Clin Biochem. 1983;21(11):709-720.

28. Carstensen B. Comparing methods of measurement: Extending the LoA by regression. Stat Med. 2010;29(3):401-410.

29. Ustün TB, Chatterji S, Bickenbach J, Kostanjsek N, Schneider M. The International Classification of Functioning, Disability and Health: a new tool for understanding disability and health. Disabil Rehabil. 2003;25(11-12):565-571.
30. Eisner MD, Iribarren C, Blanc PD, et al. Development of disability in chronic obstructive pulmonary disease: beyond lung function. Thorax. 2011;66(2):108-114.

31. Waschki B, Kirsten A, Holz O, et al. Physical activity is the strongest predictor of all-cause mortality in patients with COPD: a prospective cohort study. Chest. 2011;140(2):331-342.

32. Garcia-Aymerich J, Hernandez C, Alonso A, et al. Effects of an integrated care intervention on risk factors of COPD readmission. Respir Med. 2007;101(7):1462-1469.

33. Pitta F, Troosters T, Probst VS, Spruit MA, Decramer M, Gosselink R. Quantifying physical activity in daily life with questionnaires and motion sensors in COPD. Eur Respir J. 2006;27(5):1040-1055.

34. Asmussen E, Bonde-Petersen F. Apparent efficiency and storage of elastic energy in human muscles during exercise. Acta Physiol Scand. 1974;92(4):537-545.

35. van Gestel AJ, Clarenbach CF, Stöwhas AC, et al. Predicting daily physical activity in patients with chronic obstructive pulmonary disease. PLoS One. 2012;7(11):e48081. 


\section{Supplementary materials}

Table SI Number of rises attained at the end of each minute for the three modalities of the 3CRT

\begin{tabular}{|c|c|c|c|c|}
\hline $\begin{array}{l}\text { 3CRT quartiles }(\mathrm{Q}) \\
\text { total number of rises }\end{array}$ & $\begin{array}{l}\text { QI } \\
>54\end{array}$ & $\begin{array}{l}\text { Q2 } \\
5 I-54\end{array}$ & $\begin{array}{l}\text { Q3 } \\
44-50\end{array}$ & $\begin{array}{l}\text { Q4 } \\
<44\end{array}$ \\
\hline$I \min$ & 12 & 12 & 12 & 12 \\
\hline $2 \min$ & $23.4 \pm 6.1$ & $17.9 \pm 1.9$ & $|5.8 \pm 2|$. & $13.3 \pm 2.9$ \\
\hline $3 \mathrm{~min}$ & $22.6 \pm 3.3$ & $17.4 \pm 1.8$ & $15.2 \pm 2.0$ & II $.0 \pm 4.3$ \\
\hline Total & $58.0 \pm 9.1$ & $47.3 \pm 3.4$ & $43.0 \pm 4.1$ & $36.3 \pm 6.8$ \\
\hline$I \min$ & 15 & 15 & 15 & 15 \\
\hline $2 \min$ & $23.0 \pm 4.6$ & $18.7 \pm 0.8$ & $16.3 \pm 1.2$ & $11.7 \pm 2.9$ \\
\hline $3 \mathrm{~min}$ & $23.1 \pm 4.3$ & $\mid 8.4 \pm 1.0$ & $15.6 \pm 1.5$ & II $.2 \pm 4.3$ \\
\hline Total & $61.1 \pm 8.7$ & $52.11 \pm 1.2$ & $46.9 \pm 2.2$ & $37.9 \pm 6.7$ \\
\hline$I \min$ & 20 & 20 & 20 & $19.1 \pm 1.7$ \\
\hline $2 \mathrm{~min}$ & $22.4 \pm 2.76$ & $20.1 \pm 1.4$ & $17.9 \pm 4.7$ & $11.6 \pm 3.4$ \\
\hline $3 \mathrm{~min}$ & $22.5 \pm 4.9$ & $19.9 \pm 1.7$ & $16.4 \pm 2.1$ & $9.7 \pm 5.0$ \\
\hline Total & $64.9 \pm 7.5$ & $60.0 \pm 2.8$ & $54.3 \pm 6.5$ & $40.3 \pm 8.0$ \\
\hline
\end{tabular}

Notes: Results are shown for each quartile of the overall performance (total number of rises); the more severely impaired patients are in Q4; the total number of rises by each quartile is significantly different in all three modalities; Analysis of variance (ANOVA) for each quartile shows a significant trend of increasing total rises from 3CRT-12 to 3CRT-20 modalities; however, for the most severely impaired patients (Q4), the number of total rises in 3 minutes (min) was very similar in the 3CRT-I2 and 3CRT-20 modalities (see Figure I).

Abbreviations: 3CRT, 3-minute chair rise test; 3CRT-12, 3-minute chair rise test - 12 rises; 3CRT-20, 3-minute chair rise test -20 rises.
Table S2 Multivariate linear regression model predicting the final performance (number of rises) for 3CRT-I 2 and 3CRT-20

\begin{tabular}{lllll}
\hline & Coefficient & P-value & \multicolumn{2}{c}{$\begin{array}{l}\text { 95\% confidence } \\
\text { interval }\end{array}$} \\
\hline 3CRT-12 & & & & \\
Age & -0.48 & 0.001 & -0.76 & -0.20 \\
BMI & -1.02 & 0.01 & -1.81 & -0.23 \\
TLCO \% & 0.44 & 0.001 & 0.20 & 0.67 \\
DIRECT score & -0.66 & 0.01 & -1.16 & -0.15 \\
Constant & 88.4 & & 61.7 & 115.1 \\
3CRT-20 & & & & \\
Age & -0.55 & 0.001 & -0.85 & -0.26 \\
BMI & -1.08 & 0.011 & -1.90 & -0.27 \\
TLCO \% & 0.47 & 0.001 & 0.22 & 0.72 \\
DIRECT score & -0.76 & 0.005 & -1.28 & -0.25 \\
Constant & 103.8 & & 76.9 & 130.6 \\
\hline
\end{tabular}

Notes: The regression for 3CRT-12: $Y$ (number of rises) $=88.4-0.48$ age (year) $-1.02 \mathrm{BMI}+0.44 \mathrm{TLCO}\left(\mathrm{mL} \mathrm{CO} \cdot \mathrm{min}^{-1} \cdot \mathrm{mmHg}^{-1}\right)-0.66$ (DIRECT Score); the regression for 3CRT-20: $Y$ (number of rises) $=103.8-0.55$ age (year) $-1.08 \mathrm{BMI}+$ $0.66 \mathrm{TLCO}\left(\mathrm{mL} \mathrm{CO} \cdot \mathrm{min}^{-1} \cdot \mathrm{mmHg}^{-1}\right)-0.76$ (DIRECT Score); for 3CRT-12, $R^{2}=0.50$ and adjusted $R^{2}=0.44$; for $3 C R T-20, R^{2}=0.56$ and adjusted $R^{2}=0.50$.

Abbreviations: 3CRT-12, 3-minute chair rise test - 12 rises; 3CRT-20, 3-minute chair rise test -20 rises; BMI, body mass index; DIRECT, Dlsability RElated to Copd Tool; TLCO, transfer factor for carbon monoxide. 
Bland-Altman

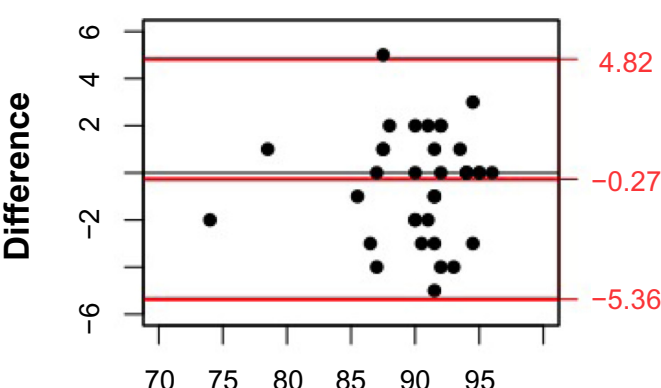

Average

Deming regression

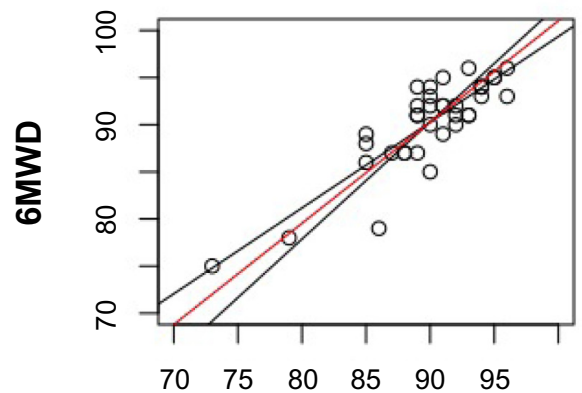

3CRT-20
Bland-Altman with smooth regression

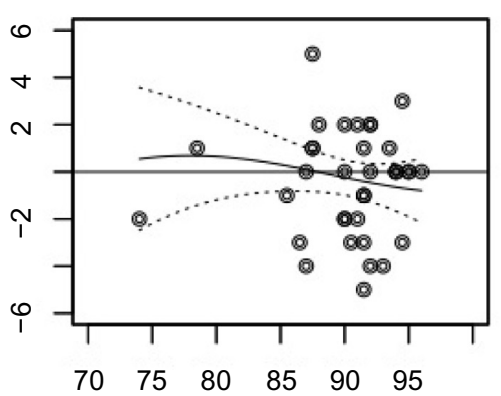

Average

Passing-Bablok regression

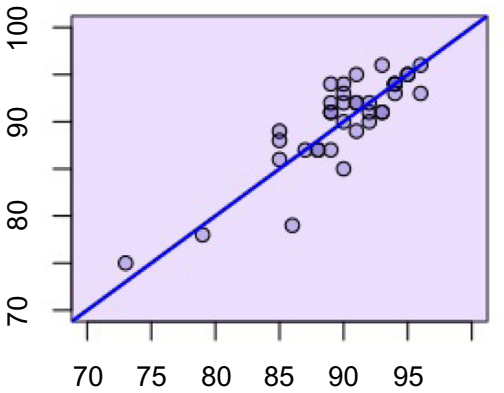

3CRT-20

Figure SI Evaluation of the interchangeability of maximal oxygen desaturation at the end of the 6MWT and 3CRT-20 in COPD patients.

Notes: Complementary statistical tests were as follows: Bland-Altman plot (bias and limits of agreement [ \pm I.96 SD]), Bland-Altman plot with smoothed regression (regression curve and $95 \% \mathrm{Cl}$ ), Deming regression (regression of each method on the other in black, Deming regression line in red), and Passing-Bablok plot (regression line with $95 \% \mathrm{Cl}$; the blue color of the figure indicates that all data are in the $\mathrm{Cl}$ ).

Abbreviations: 3CRT-20, 3-minute chair rise test - 20 rises; 6MWD, 6-minute walk distance; 6MWT, 6-minute walk test; Cl, confidence interval; COPD, chronic obstructive pulmonary disease; SD, standard deviation.

\section{Publish your work in this journal}

The International Journal of COPD is an international, peer-reviewed journal of therapeutics and pharmacology focusing on concise rapid reporting of clinical studies and reviews in COPD. Special focus is given to the pathophysiological processes underlying the disease, intervention programs, patient focused education, and self management protocols

\section{Dovepress}

This journal is indexed on PubMed Central, MedLine and CAS. The manuscript management system is completely online and includes a very quick and fair peer-review system, which is all easy to use. Visit http://www.dovepress.com/testimonials.php to read real quotes from published authors. 